\title{
12. Beep: Listening to the Digital Watch
}

\author{
Sumanth Gopinath
}

\begin{abstract}
This essay considers the intertwined histories of the word "beep" and the simple, single-oscillator tone by examining the digital watch of the late 1970s-early 1980s. The watch and its beep marked a key economic and technological development in which the US, as global hegemon and economic powerhouse, was not the dominant agent. They also prefigured the tinkling sound of ringtones on mobile phones and initiated the mass mundanization of digital beeps, now shorn of the symbolic power of recondite, expensive, and classified Cold War-era technologies. The watch beep's hardwired nature allows us to hear connections between that historical moment's different temporal scales, direct linkages between which would soon be imperceptible thanks to the digital economy's ever increasing abstraction.
\end{abstract}

Keywords: beep, digital watch, sound studies, piezoelectricity, world-systems theory, integrated circuit (IC)

Beep. This word denotes several associations in English, including its noun and verb forms, its evocative epizeuxis beep-beep, and its description of a device, the beeper. The Oxford English Dictionary reveals that the beep is a twentieth-century phenomenon, initially indexing the bustling modernity of urban soundscapes and transit and expressed through the obtrusive car horn. ${ }^{1}$ Plosives in the word's beginning (voiced) and ending (unvoiced) frame a close front unrounded vowel that accentuates higher frequency content, particularly in American English. Sounding like the signal it describes, the word's onomatopoetic qualities grab your attention, quickly. The oldest relevant entry in the dictionary is Edmund Wilson's first novel I Thought ofDaisy (1929), as spoken by the titular character, Daisy Coleman, a chorus girl who is the narrator's love interest and who describes car horns thusly:

Volmar, A. and K. Stine (eds.), Media Infrastructures and the Politics of Digital Time: Essays on Hardwired Temporalities. Amsterdam: Amsterdam University Press, 2021 DOI 10.5117/9789463727426_CH12 
“'It's a shout. There's a toot-toot, and a beep-beep - and an oorah-and a blah-blah, and a blurp-blurp. - Dad's was a kind of a oorah - and it was a humdinger, too!"2 The horn's sound is not uniquely captured by "beep," and today a horn is typically described as honking. A search of The New York Times reveals that the word doesn't appear in the paper until the 1930s, when describing a bicycle horn. ${ }^{3}$ In the postwar period, "beep" expanded beyond vehicular horns to designate electronic signals, including those in military technologies, touch-tone dialing, and other telephonic sounds; ${ }^{4}$ experimental electronic music and its uneven migration into pop/rock; science fiction and space travel (partly via the Sputnik beep); ${ }^{5}$ and radio alert and signal-scrambling systems like CONELRAD (Control of Electromagnetic Radiation) and the Emergency Broadcast System (EBS). ${ }^{6,7}$ The expanded use of the word "beep" suggests that beeps became central to the US Cold War soundscape.

But if the initial conjoining of the beep and single-oscillator signal occurred during the period spanning the late nineteenth century and World War II, and a new crystallization began after the war, it would be the long 1970 s that made the beep newly ubiquitous by embedding them into devices large and especially small: appliances, phones, games, computers, and pagers. Moreover, due to the global growth of Japanese electronics production and sales, the story was no longer predominantly a US-centric one. Making that technological and sociocultural transformation possible was the rise of semiconductor electronics, which enabled smaller and smaller components to be tucked away silently into ever more ubiquitous devices. As Ross Bassett puts it, the semiconductor transistor "is a base technology of late-twentieth-century and early-twenty-first-century America. Through it digital electronics have entered almost every area of American life, first through the calculator, then through the digital watch, and finally through the microprocessor." 8 Despite their pervasiveness in America and worldwide, microelectronics are unseen and unheard, known only through their effects. It is fitting that they have been accompanied by equally ubiquitous, beeping small speakers. ${ }^{9}$

The widespread mundanization of the smartphone and hence portable personal computer, with its sophisticated audio generation and playback capabilities, have seemingly propelled the world into a newly intensified dependence upon and engagement with integrated circuits (ICs), microprocessors, and the complex sounds they enable. But we still live in the era of the beep, which is unlikely to disappear anytime soon, given its utility and simplicity. If the beep acts as a deep social layer composed of myriad hardwired temporalities that continues to either interact with or ignore 
sound reproduction, ${ }^{10}$ its formation merits further investigation. A crucial development in the beep era is that of digital watch, in which the IC met the beep in a mobile, mass-market context for the first time.

The history of the digital watch is complex and dramatic. It involves the belated application of the nineteenth-century discovery and theorization of piezoelectricity, international economic battles between the established Swiss mechanical watch industry and newer, upstart watch industries based in the United States and Japan, ethico-moral debates over the importance of learning to read the analog clock face, ultimately leading to its coexistence with the numerical watch display, and the inauguration, along with the calculator, of a series of consumer fads for digital devices beginning in the 1970s. In what follows, I consider the digital watch at multiple temporal scales. First, I recount the long history of the watch industry's transnational political economy, including its transition to digital timekeeping. The industry's temporality is interpreted here at the macro-temporal level of Arrighi's "long century," in ways that dovetail with the century-long, US-hegemonic history of the "beep" word and concept. ${ }^{11}$ I then explore the micro-temporality of the digital watch, as produced by the piezoelectricity of quartz crystals and microprocessor-calculated digital timekeeping. I continue by examining the digital watch's sounds and end by noticing their presence in social spaces; these sounds seem to exist at a widely meso-temporal scale from minutes to months and years. The patterned alignment of these particular components and their corresponding social practices can be interpreted as a form of hardwired temporality, but the simplicity of the micro-temporal components in early mass digital timekeeping allowed a direct and perceptible connection via the meso-temporal. To anticipate my conclusion, listening to the digital watch allows us to further connect these temporal scales, by articulating a beep (and its means of generation) with the incipient decline of US economic hegemony. By becoming quotidian, the beep-which prefigured the more versatile and abstracted mobile phone and its sounds-lost its valences of power and potential.

\section{The Political Economy of the Watch Industry}

The digital watch upended the traditional global hierarchy of the watch industry, leading to the divide between luxury and economy exports stemming primarily from Switzerland and East Asia, respectively. Before the digital watch's emergence, the industry was dominated by Swiss watch firms, as it had been since the mid-nineteenth century. ${ }^{12}$ That dominance was arguably 
a hard-won product of economic and technological contestation in Europe over the course of the early modern period. Several contributing factors include the emigration of French Hugenot watchmakers to Switzerland in the sixteenth century, which brought crucial new talent to the country and arguably crippled French watchmaking; the peculiar form of decentralized social conservatism characteristic of Swiss industries, leading to the gradual adoption of institutional changes and greater inclination toward honing existing practices; and its comparatively high ratio of watchmakers to parts manufacturers, encouraging the creation of a greater variety of products in different price ranges. ${ }^{13}$ These developments led watchmakers in Geneva to become increasingly competitive with the more established British watchmaking industry in the eighteenth century. Then, with the rise of yet another Swiss region for watch production in the Jura mountain valley region, centered in Neuchâtel, in combination with generally lower wages in Switzerland, the country's products began to undercut British sellers at the end of the eighteenth century and into the nineteenth century. Long being an emulative industry up to the mid-eighteenth century, following innovations from Britain or France, Swiss watchmakers increasingly took the lead in new development, creating standardized tests, competitions, and watchmaking schools, all with the strong support of the state and contributing to Swiss preeminence in watch production by the mid-nineteenth century.

The primary contender for industrial dominance in the mid- to late nineteenth century was the US. Driven by the demands of railroad scheduling, the US watch market was temporarily closed to exports due to wartime protectionism during the Civil War, giving a boost to postbellum industrial growth in US watch manufacturing, which became increasingly rationalized. US firms soon became strongly competitive with Swiss makers, who were slow to adopt factory production methods. Industrialized US watch firms, such as the Boston-based Waltham Watch Company, were of crucial importance in establishing the quality of US watches, and the Elgin Watch Company, located near Chicago, in turn drew on the expertise (and sometimes personnel) of Waltham, leading to a powerful, two-company trust at the forefront of the US watch industry in the late nineteenth century; the Hamilton Watch Company, based in Lancaster, Pennsylvania, was another important late entrant into the market that would assume an ever stronger role among US firms. And yet, in $1885^{-1905}$, the Swiss watch industry upgraded itself partly on the American model, reducing small-scale production and moving toward vertical integration, and by 1910 Swiss watches again dominated the global market. Crucial was the rise of the wristwatch (instead of the older pocket watch), which Swiss makers produced more successfully 
than US firms, who were hampered by "a uniform regulatory regime for the production of railroad watches using machine-manufactured parts." ${ }^{14}$ Swiss watch industry dominance continued through the interwar and early postwar periods, with market share for low-end watches only facing significant competition from US-based Timex in the 1950s and 196os.

The rise of the Japanese watch in the 1960 s and after was completely unexpected by the Swiss and American watch industries. Although Japan industrialized in the nineteenth century and sustained a sizable watch industry led by Seiko, Citizen, and Ricoh in the early twentieth century, its greatest advances in the watch industry occurred during the renewed industrialization of the postwar period, after the devastating WWII bombing of its factories and productive forces. Its credentials were boosted by a key development. As Amy Glasmeier notes, "When Seiko was selected as the timekeeper for the 1964 Winter Olympics, held in Sapporo, Japan, its reputation was greatly enhanced. In full view of the entire world, the Japanese watch company demonstrated what had heretofore been the exclusive purview of the Swiss: to flawlessly keep, record, and display time at exceptionally high levels of accuracy."15 But the critical commodity for the Japanese watch industry was the digital watch, which ultimately led Japan to become the world's largest watch producer, with annual production figures growing from nearly 700,000 to over 86,000,000 watches from $195^{\circ}$ to $1980 .{ }^{16}$ US-American and Japanese scientists and companies collaborated and competed in producing high-quality ICs (and later liquid crystal displays or LCDs), first used in calculators and then watches: when they entered some aspect of this market at all, US electronics firms often gave up on or mistimed their investments in these technologies, to the benefit of Japanese producers. ${ }^{17}$

Despite the relative weakness of the US watch industry after WWII, it was competition between American and Japanese firms that would prod the development of the digital watch, with the latter ultimately winning out. After creating initial prototypes, Swiss firms stayed on the sidelines to their detriment - until Swatch, founded in 1983, helped put an end to the "quartz crisis" of that country's watchmaking industry. ${ }^{18}$ In retrospect, the earlier rise of American timekeeping - in contrast to the longer-established British and Swiss industries - signaled the corresponding rise of US-American hegemony in surprisingly direct ways (with the British watch industry's supersession and Swiss industry's development arguably linking not only to the early-modern-historical lineage mentioned above but also to the decline of British hegemony and to central-European bids for global dominance in the mid- to late nineteenth and early twentieth centuries, respectively). 
This narrative suggests that the timekeeping business was fundamental to the capitalist world-system more broadly-which might be expected, given the essential role of clocks in the management of modern markets, transportation, labor, and state administration. The Japanese development of the digital watch likewise signaled a new possible capitalist hegemony in East Asia-later furthered by China's emergence as "the workshop of the world." ${ }^{19}$ Bound up with the long century of American hegemony, the beep was absorbed and expanded dramatically in Japan and East Asia, alongside digital devices more generally. ${ }^{20}$

\section{Piezoelectricity and the Quartz Watch}

The foundation of quartz timekeeping is the phenomenon of piezoelectricity. Discovered by Jacques and Pierre Curie in 1880, it involves the generation of an electrical polarization by applying mechanical stress to certain materials, especially crystals, metals, and ceramics. This polarization creates the possibility of generating an electrical current from mechanical pressure to a piezoelectric material, but the reverse effect - generating a mechanical movement from an electrical charge — was also predicted by Gabriel Lippmann one year after the Curies' discovery. Although the basic mathematical theorization of piezoelectricity was completed by Woldemar Voigt in 1890, it was first employed in devices during WWI, when early efforts to detect submarines via ultrasonic waves (later termed SONAR by the US military) made use of quartz-based transducers. In 1921 Walter Cady created the first quartz crystal oscillator, and in 1927 scientists at Bell Labs produced the first quartz clock, using quartz as a stable oscillator. ${ }^{21}$

With the emergence of the integrated circuit in the 1960 , quartz clocks came into widespread use; their basic principle can be understood as follows (fig. 12.1). First, a battery (b) powers a transistor oscillator (not shown) that activates the crystal resonator $(a)$, causing it to vibrate and hence transform electrical energy into elastic energy. The resonator smooths out the irregularities of the oscillator, thanks to the very low power loss and high stability of the quartz crystal. The resonator then reconverts the vibrations into a highly stable electric current, sending it to the microprocessor $(d)$, which counts the number of pulses from the quartz (which is conventionally designed to oscillate at 32,768 or $2^{15} \mathrm{~Hz}$ ). The microprocessor then repeatedly divides the pulses by 2 in order to reach $1 \mathrm{~Hz}$ (or 1 cycle/second) for the purpose of keeping time. The output information is then sent to the digital display $(e)$ or, if it is an "analog" quartz clock, to a watch movement mechanism that 


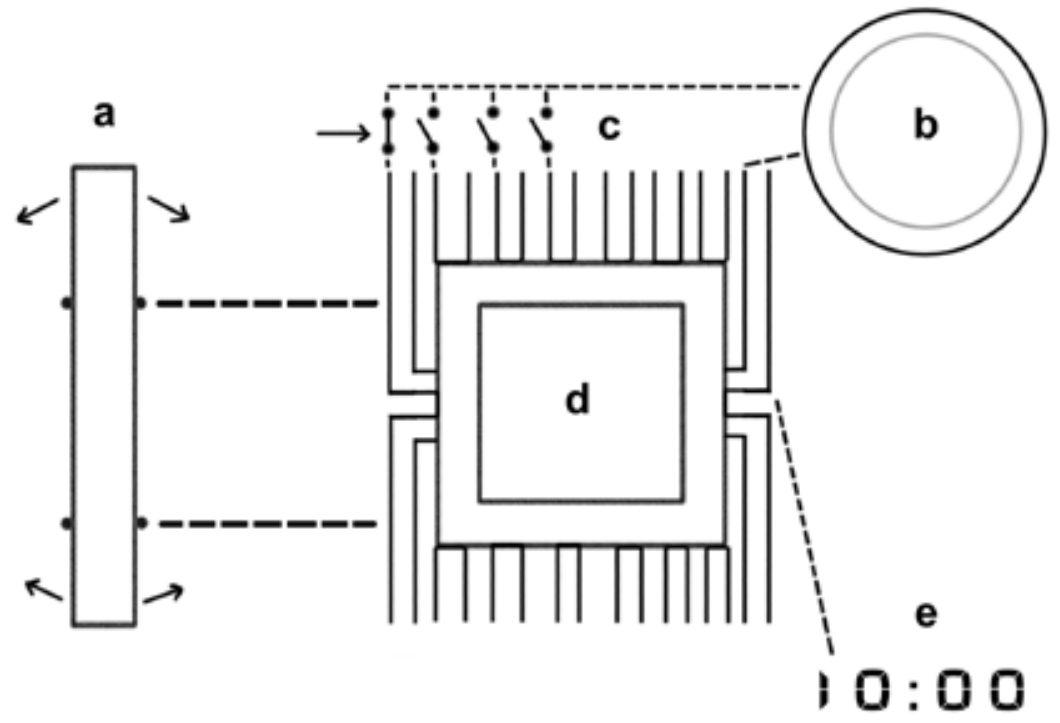

Figure 12.1. Diagram of the quartz wristwatch structure, after David Penney, in David Landes, Revolution in Time: Clocks and the Making of the Modern World (London: Viking, 2000), p. 376.

moves the second, minute, and hour hands of the clock face. (Hence, we appreciate that just about all watches today, irrespective of their display method, use digital timekeeping circuitry - even though "analog" quartz clocks are typically described as "electronic" rather than "digital." Mechanical watches, presently a tiny minority of watches worldwide, are identified by smooth, rather than pulsed, second-hand movement.) In a digital display, a number of switches $(c)$ are also used to control other, ancillary functions like the alarm, stopwatch, and light, and thus are also mediated by the microprocessor. ${ }^{22}$

In concerning the sonic aspects of the digital watch, we must further examine and contextualize the series of switches $(c)$ that drive the watch's ancillary functions. The earliest digital watches were sold as luxury goods, in part as a result of the initial high cost of the timing circuits, and generally competed in the high-end watch market. The first electronic ("analog") quartz watch on the market, the Astron SQ made by the Japanese maker Seiko, was released in 1969 for $45^{\circ}, 000$ yen (or $\$ 1,25^{\circ}$ US), on the heels of several successful prototypes produced in Switzerland at the Centre Electronique Horloger (CEH) for competition in the Neuchâtel time trials in 1967. The American maker Hamilton, abandoning its unsuccessful efforts to produce an analog quartz watch, sought instead to make a fully digital watch, with a red light emitting diode or LED-based numerical readout 
partly inspired by Hamilton's digital timepiece for the film 2001: A Space Odyssey (1968). ${ }^{23}$ Featured in the James Bond film Live and Let Die (1973), the Pulsar cost \$2,100 upon first release in $1972 .{ }^{24}$ However, the price of microelectronics components soon dropped precipitously, inaugurating a series of price wars within the industry. As Amy Glasmeier notes,

From 1974 to 1975 , the price of a digital watch dropped from $\$ 125$ to $\$ 50$. The next big step downward was forecast for 1977 : some industry watchers believed that prices would fall to $\$ 20$. Then Texas instruments stunned the market by introducing a plastic-encased digital watch for $\$ 9.95$ ! The actions of Texas Instruments were quickly followed by other semiconductor makers who hoped to destabilize and thwart further actions by watch assemblers who could not buy components cheaply enough to compete at the $\$ 20$ level ... once Timex's exclusive domain. ${ }^{25}$

The increasing overcapacity of the semiconductor industry signaled the end of the integrated circuit's "market-pull" phase, in which demand for new semiconductors clearly outstripped production rates, to a new, "technology-push" phase in which semiconductor manufacturers pushed their way into new industries like watchmaking and undersold established firms to meet the demands of expanding fixed capital sunk in production equipment and facilities. ${ }^{26} \mathrm{~A}$ new, mass-oriented, spectacularized sales ethic soon replaced the older, luxury-goods oriented marketing strategy, as seen in a comparison between a mid-1970s watch ad by the Swiss-British luxury brand Rotary (featuring an older, less efficient red LED display) and a 1978 Seiko Memory Bank Calendar Watch commercial (featuring the then-newer LCD, science-fictional synthesizer music, and a tech-functional ethos). ${ }^{27}$

The micro-temporality of the digital watch was bound up with new economic realities within the industry: it was cheaper and more accurate, and its digital temporalities bypassed the previous mechanical temporalities of the traditional watch movement. The digital watch's temporality had new visual indicators, chiefly the display that read out digits instead of hands on a dial, but also its employment of a microprocessor and speaker system that typically resounded its inner workings through a beep.

\section{The Sounds of the Digital Watch}

Within an increasingly competitive sales environment, companies in the mid- to late-197os began producing multifunctional watches, including 
calculator and calendar watches, and incorporated sound into them. Some early digital sound watches were alarm watches, and the alarm soon became standard on digital watches, which often emitted short beeps when a button was pressed. ${ }^{28}$ Among the earlier examples included the 1977 Seiko Ao39 Quartz LC Alarm Watch, which featured two different alarms with two volume settings, an hourly signal, and a stopwatch function (likely including start and stop beeps). By the turn of the new decade, novelty sonic watches emerged, including some that played several different melodies, offered video games, and even talked in the case of the OMNI Voicemaster. According to one news article, this latter product "looks like a normal digital watch but, when a small button next to the face is pushed, a male voice announces the time-hour, minutes and a.m. or p.m. The timepiece also has a 24-hour alarm - with the tune of Boccherini's Minuet. When the set time arrives, the watch states the time, then plays a melody for about 20 seconds. Unless the wearer resets the alarm control within five minutes, the watch announces 'Attention please,' repeats the time and urges 'Please hurry.' The watch can also be used as a talking stopwatch." ${ }^{29}$

Perhaps the most important of these watches in terms of sales and musical content were the Casio Melody Alarm watches first appearing at trade shows in 1980 and released on the market the following year. ${ }^{30}$ These watches featured twelve melodies, divided into two groups. The first group, consistent across most of the watches, provided alarms on the hour or as coordinated with the watch's calendar function, such as playing "Happy Birthday" on a designated birthday, "Jingle Bells" on Christmas Day, the "Big Ben" chime for hourly alarms, and Mendelssohn's "Wedding March" for a wedding or anniversary. The second group involved daily alarms that varied more frequently according to watch model; in each model, however, the alarm was one of seven melodies coordinated with the days of the week. The variety can be seen across two production batches of the Casio Hio4 Melody Alarm Watch with different pre-programmed melody modules (table 12.1). Module 82 features a weekly schedule beginning with F. W. Meacham's 1885 march "American Patrol" on Monday and a number of European "folk songs" from Tuesday to Friday, before ending on the weekend with the Japanese song "Sakura Sakura" on Saturday and the main tune of Schubert's Moment Musical No. 3 on Sunday. The melody collection here seemingly trumpets Japan's recent inclusion into the global north and group of politically powerful nations, comprising the US and most of the dominant European countries (France, Russia, Italy, Spain), with Sunday being reserved for an Austrian classical composer. ${ }^{31}$ Module 142 , in contrast, is more scattershot and less inclusive internationally. 
Table 12.1. Casio H104 melody watch instructions, listing of melodies for two separate sound-production "modules"

\begin{tabular}{ll} 
& \multicolumn{1}{c}{ (Module No. 82) } \\
\hline $\begin{array}{l}\text { Day of week } \\
\text { Monday }\end{array}$ & Melody \\
Tuesday & American Patrol (F. W. Meacham) \\
Wednesday & Santa Lucia (Napoles folk song) \\
Thursday & Marche Royale (French folk song) \\
Friday & Kalinka (Russian folk song) \\
Saturday & Sakura Sakura (Japanese folk song) \\
Sunday & Moments musicaux (Franz P. Schubert) \\
\hline & \\
\hline $\begin{array}{l}\text { Day of week } \\
\text { Sunday }\end{array}$ & Melody \\
Monday & Ungarische Tanz, Nr.5, F moll (Brahms) \\
Tuesday & "Carmen." Votre toast, je peux vous le rendre (G. Bizet) \\
Wednesday & Little brown jug (American folk song) \\
Thursday & L'amour est bleu (Andre Popp) \\
Friday & A walk in the Black Forest (Horst Jankowski) \\
Saturday & Yellow Rose of Texas (American folk song) \\
\hline
\end{tabular}

It is weighted more heavily toward classical music (Brahms, Bizet, and Mozart), with some Europop (André Popp), European easy listening (Horst Jankowski), and a couple of nineteenth-century US minstrel tunes described, again, as "folk songs" ("Little Brown Jug" and "Yellow Rose of Texas").

With the exception of Popp, Jankowski, and "Happy Birthday," these melodies were no longer protected by copyright and could be adapted freely. However, at least one version of the watch (perhaps the M-1230) reproduced mostly English-language popular songs from the 1960s and 1970s, including "Never on Sunday" (a Greek and then English-language hit song from the same-titled 1960 film), Simon and Garfunkel's "The Sound of Silence" and "Scarborough Fair (Parsley, Sage, Rosemary and Thyme)," the Beatles' "Ob-La-Di, Ob-La-Da," "Rhythm of the Rain" (a 1962 hit for the Cascades), and Billy Joel's "The Stranger" (1977). These copyrighted tunes were likely used without proper licensing or royalty payments. (This was well before the US/UK music publishing industry had become extremely driven to secure intellectual property rents in all possible venues, and Japanese corporations' geographical, linguistic, and legal distance surely hampered enforcement.) 
Finally, some Casio Melody Alarm watches included an LCD scale-display showing notes corresponding to each melody's pitches-specifically, their white-key equivalents or counterparts represented within a C-diatonic gamut, like a visualization of fixed-do solfège. Casio and other companies eagerly demonstrated the utility of LCDs: some of their watches utilized an LCD dial imitating the analog clock face, while others used the display for portable video games.

By the 1980 s, sounds on these watches were usually made by piezoelectric speakers, which were developed over the course of the 1970s. Using the same effect as the quartz timekeeping mechanism, a piezoelectric speaker is a small transducer that transforms electrical signals into mechanical energy without the mediation of a wire coil or magnet (as with standard speakers). Scott Chou of Hattori Seiko Co. (Seiko's name in 1983-1990), noted in 1989 that in most watches the piezoelectric element is a type of ceramic foam connected to a thin silver contact, resonating at a frequency of about 4,000 $\mathrm{Hz}$ and taking advantage of the human ear's great sensitivity at 4,000-6,000 $\mathrm{Hz} \cdot .^{32}$ The benefits of the piezo speaker were multiple. It required low power, a primary concern during the 1970 (the red LED display fell out of favor partly due to power needs). Like the watch mechanism itself it was highly reliable. And, most importantly, it was remarkably compact - taking up almost no space within the watch itself (present-day digital watches nestle it snugly between the microprocessor and the battery).

Chou's description of the alarm's frequency seems correct: the standard digital watch beep is set at $4,096 \mathrm{~Hz}$, the oscillating frequency of the piezoelectric quartz crystal, $32,768 \mathrm{~Hz}$, divided by $2^{3}$ or undergoing a half division three times. The watch alarm uses the original oscillating frequency as the quartz watch timekeeping system to power the alarm, almost certainly using the same microprocessor to compute the alarm's frequency. The pitch is a very high $\mathrm{B} 7$ or flat $\mathrm{C} 8$ (about 38 cents flat). Other digital alarms and signals use the same principle, sounding at the same frequency or an octave or two below-2,048 Hz (or high $\mathrm{B} 6$, flat $\mathrm{C}_{7}$ ) or 1,024 $\mathrm{Hz}$ (or high $\mathrm{B}_{5}$, flat $\mathrm{C6}$ ). In the earliest watches, cost was likely a determining factor in the selection of the alarm frequency; the alarm had to be solidly within hearing range, and $8,912 \mathrm{~Hz}\left(32,768 \mathrm{~Hz}\right.$ divided by $\left.2^{2}\right)$ is a little bit high to be effective as an alarm (and much less audible for elderly hearing people ${ }^{33}$ ). The highest possible frequency would entail the smallest number of half-divisions (which would not necessarily mean a cheaper circuit - that would depend on the most efficient Boolean logical reduction of the alarm clock circuit). Given the frequency's commonness, it is possible that 4,096 $\mathrm{Hz}$ requires the smallest (and likely cheapest) piezoelectric sounder needed 
to produce the sound. Moreover, since low frequencies generally require more power to be heard and given this frequency's placement within the maximally perceptible frequency range of hearing, it probably uses the least battery power. ${ }^{34}$

\section{The Social Fallout of the (Sounding) Digital Watch}

If the macro-temporality of the digital watch industry is its long centuries and the micro-temporality of the digital watch is its quartz crystal vibrations, it is the meso-temporality of the watch's use, including its beeps, that has shaped everyday life. Minutes, hours, and days structure that use, through its orientation toward the working day; the watch's alarms enact both the production of labor discipline (such as daily waking for work) and reproductive leisure (such as the late 1970s and early 1980s running boom, to which its stopwatch function became fundamentally tied). ${ }^{35}$ Weeks, months, and even years were marked by additional uses, from the calendrical functions identifying the first two to the longer periodicities of leap-year date corrections or replacing the watch's battery, acts all accompanied by ever-present beeps.

For a time, the digital watch seemed to be everywhere. Indeed, during the 1980 s, a considerable ressentiment against it gathered steam, with much of the energy trained upon the digital time display. As James Sterba wrote in 1982,

The anti-digit traditionalists have staged a comeback in the last few years, partly by stealing a word from the computer business - analog - to space-age the name of their old standard bearer. It is no longer just a watch. It is an analog watch, which means it represents one quantity - time - by another quantity, the motion of its hands on a dial. They argued that there might be hidden danger to children, growing up on digits, who could read time by simply knowing numbers but could not discern it analogously from a watch or a clock with hands. ${ }^{36}$

Aiding the antagonists were the perceived sonic failings of the digital watch; as the watch historian and partisan for the old mechanical watch movement David Landes argued, "the tick of a good timepiece is a delight to those who can appreciate a strong, regular beat," whereas the British designer Richard Porch complained that the digital watch is "a silent affair that requires no attention." 37 Except, of course, when it beeps-especially as it often does on the hour, every hour, with a quasi-humanizing or 
science-fictional chime likely intended to give some sonic character to the otherwise silent device. Indeed, the collective annoyance with the digital watch came to the fore in public art and performance spaces, generating a mild "digital watch rage" recalled two decades later by ringtone rage in similar circumstances. One journalist connected such experiences to broader frustrations with the beep:

The contemptuous little "beep" never comes at the crescendo of a Wagner symphony. It happens only during a dramatic pause in Hamlet's soliloquy, the turning point in a critical sales presentation, or at the perfectly inappropriate moment of a torrid love scene. In the worst case, a sudden, uncontrollable beep has the same social impact as a sudden, uncontrollable belch. If digital watches were the only devices openly mocking their owners, life in the Technobabble Jungle wouldn't be so frustrating. ${ }^{38}$

But a major difference between more recent cellphone interruptions and digital watch intrusions is the regularity (and predictability) of the routine. One editorial writer lamented,

To be in a movie theater now as the hour changes is to hear a beep chorus. It sounds as though half the audience is wearing those digital watches that emit one beep on the half-hour and a vigorous beep-beep on the hour. The chorus would be tolerable if everybody's watch chimed in unison. But the movie theater beep-beeps start around 8:58:30, gather in a crescendo, and then sputter along until 9:02 or so-a longish distraction, and a puzzling one. ${ }^{39}$

The opponents of the fully digital watch and its beeps won out, relegating the device to second-fiddle status within the industry and restoring the analog dial to its once-primary position..$^{40} \mathrm{But}$, as historians Carlene Stephens and Maggie Dennis put it, "Behind the dial of most new watches, though, hummed an electronic heart. ${ }^{\prime 41}$ Indeed, by 1997, mechanical watches accounted for only 7.9 percent of total volume and 44 percent of sales value globally. But the beeping digital watch had the last laugh: the same basic principle of sound production made its way into the mobile phone, providing the technological basis for the extremely annoying monophonic ringtone during the 1990s and early 20oos. Synchronized to cellular networks, the beeping phone became the new digital watch; in doing so, it bypassed the problem of accurate, device-based timekeeping altogether. 


\section{Conclusion}

Despite the appearance of critically praised, wrist-based devices such as the Pebble Watch, Samsung's Galaxy Gear, and the Sony SmartWatch and the popular self-generated-data-tracking device FitBit, no device has yet inspired a sufficient degree of excitement to propel wrist-based wearable devices into the leading edge of popular technology consumption in the new millennium. The closest exception might be the Apple Watch, first released in 2015. ICT industry boosters hoped that the device would do for the smart watch what the iPhone did for the smartphone and the iPad for the tablet computer, and although its popularity is steadily rising, it is difficult to predict its future..$^{42}$ It initially targeted tech enthusiasts, fitness watch users, Quantified Self movement participants, wealthy consumers, and those nostalgic for outdated science-fiction protagonists, including Knight Rider's Michael Knight, Inspector Gadget's niece Penny, and Dick Tracy. For now the Apple Watch is still most functional when tethered to an iPhone. ${ }^{43}$ But it can make the same preset ring and alert sounds as the iPhone, and, like many phones today, these functions are frequently silenced.

The smartwatch commodity could help to close the gap created by the mobile telephone, which in the early to mid-2ooos caused a precipitous drop in wristwatch sales among younger consumers especially. ${ }^{44}$ The conflict between watch and phone- two technologies that offer what Landes calls "cheap time"45 — masks how they have influenced one another, particularly in the era of the integrated circuit, which permits a degree of repurposing remediation hitherto unimaginable. The digital watch, an early wearable digital technology, was a precursor to the modern mobile phone, particularly in the way it accumulated features, including some of the same sonic ones. By listening to the digital watch, we learn something about not only the relationship between two world-historical devices but also the corresponding states of the capitalist world-system that made their emergence possible.

The parallels between the respective sounds of the digital watch and the mobile phone are easy to draw. ${ }^{46}$ The digital watch's beep became the simple digital ringer of the mobile phone, and the melodic watch became the monophonic ringtone. Ringtone rage in the public sphere and at performances in the early 2000 s was prefigured by the public disturbances of the half-hourly chimes of the digital watch two decades earlier. Both the digital watch and mobile phone used their sound production systems to incorporate timers and handheld video games, and the digitized voices of novelty watches even anticipated the voice assistants of Siri, Cortana, 
and Alexa. And, the global political economies of both devices revealed a tripolar dynamic, with competition between specialized locales in Europe (Switzerland and Nokia's Finland) and Japan and the US being relatively shut out of the process while previously contributing technologies that were transferred outward (integrated circuits and cellular telephony, single-oscillator tone-generators and FM synthesis). Moreover, the digital watch's trebly, tinkly beep presaged the monophonic ringtone's aesthetics, which are arguably a sonic corollary of global-regional cute (kawaii) culture-a culture that articulates unevenly with Japanese state-economic power and now exists worldwide, including in the US. ${ }^{47}$ But the differences in device purpose and design and the historical contexts of technological development reveal clear dissimilarities: with the digital watch, there was no progression in sonic fidelity, exhibited by the shift from monophonic, to polyphonic, and to sound file as with the ringtone (and numerous precursor technologies); nor did the digital watch make its tunes programmable or uploadable, leading to a lucrative para-industry comparable to the ringtone industry. And the flexibility of assigning distinct sounds to different contacts, functions, and apps in the cellphone (and smartphone and smartwatch) bespeaks a world of distributed, individualized labor-time management exploited by the digital gig economy and only hinted at by older multifunctional digital watches. ${ }^{48}$ Indeed, it is the very rigidity of the simple digital watch's beep-unlike the flexibility of and rapid changes in the mobile phone's sonic production - that allows one the rare possibility of hearing the micro-temporality of the digital watch. It is the watch's de facto employment of "scientific pitch," or $\mathrm{C}=256 \mathrm{~Hz}$ (rather than the currently standard $261.63 \mathrm{~Hz}$ ) that allows one to perceive, via a specific tuning, the inner workings of the quartz crystal, whose resonating frequency is just another flat $\mathrm{C}$, out of hearing range, and whose microprocessor divisions by two transpose it into audibility and then back out of it, as it accurately calculates the length of a second. ${ }^{49}$

In comparing the digital watch and the mobile phone, history would seem to have repeated itself as tragedy and then farce, to invoke the now-clichéd dictum from Marx's The Eighteenth Brumaire. But if the mobile phone's ringtone was clearly the farcical repetition of a phenomenon past, what was tragic about the digital watch's beep? To revisit our initial discussion, perhaps it lies partly in the epochal routinization of the ubiquitous and now-residual "beep," found in numerous household, personal, and industrial devices-microwave ovens, washing machines, scanners, digital alarm clocks, automobiles, cellular phones, home computers - and which since the 1970 s were predominantly made by integrated circuits, small speakers, and simple, single-oscillator signals. The oscillator's beep, at one time, held 
a utopian promise, but the signal beeps from Sputnik now sound like an alarm clock; the conquest of nature and space that they represent once foretold of human betterment and today seems untenable. It is a state of affairs worthy of a cold, clear-eyed tear or two.

\section{Notes}

Many thanks to the individuals who graciously gave me feedback on or help with versions of this project, including Kate Altizer, Peter Burkholder, Phil Ford, Anand Gopinath, Sudhir Gopinath, Beth Hartman, Karen Ho, Marianne Kielian-Gilbert, Michael Klein, Ajay Limaye, Tom McAuley, Dan Melamed, Ali Momeni, Alex Monae, Tina Muxfeldt, Ayana Smith, Jason Stanyek, Jonathan Sterne, David Valentine, Christine Wisch, and the editors-with profuse apologies to those I've momentarily forgotten.

1. Oxford English Dictionary, s.v., "beep," https://oed.com/.

2. Edmund Wilson, I Thought of Daisy, ed. Neale Reinitz (Iowa City: University of Iowa Press, 2001 [1929]), 253-54.

3. A bicycle display ad for Gimbels department store lists "a small beep-beep French horn" for 74\$. New York Times, June 5, 1933, 6.

4. See Axel Volmar, "Productive Sounds: Touch-Tone Dialing, the Rise of the Call Center Industry and the Politics of Virtual Voice Assistants," in The Democratization of Artificial Intelligence: Net Politics in the Era of Learning Algorithms, ed. Andreas Sudmann (Bielefeld: Transcript, 2019), 55-75.

5. In 1957 a retailer in Kansas City, MO had the Sputnik beep recorded and pressed onto vinyl records, selling them for \$2.95. See Mark Shanahan, Eisenhower at the Dawn of the Space Age: Sputnik, Rockets, and Helping Hands (Lanham, MD: Lexington Books, 2017), 82. Thanks to Dan Melamed for mentioning Sputnik.

6. Peter E. Hunn, "CONELRAD," in Christopher Sterling, ed., Encyclopedia of Radio, vol. 1 (A-E) (New York: Fitzroy Dearborn, 2004), 605-607.

7. Bob Dylan mentions CONELRAD in the ninth verse of "Talkin' World War III Blues" (1963), and in the tenth verse he mentions dialing the operator and hearing "When you hear the beep it will be three o'clock"; the song juxtaposes two contemporaneously prominent beep contexts.

8. Ross Bassett, To the Digital Age: Research Labs, Start-up Companies, and the Rise of MOS Technology (Baltimore, MD: Johns Hopkins University Press, 2002), 1.

9. See Jeffrey Zygmont, Microchip: An Idea, Its Genesis, and the Revolution It Created (Cambridge, MA: Perseus Publishing, 2003), xviii and passim. For example, early personal computer speakers producing simple beeps were called "bippers" or "beepers"; see Karen Collins, Game Sound: An Introduction to the History, Theory, and Practice of Video Game Music and Sound Design (Cambridge, MA: MIT Press, 2008), 29. 
10. On the functional and historical differences between sound reproduction and synthesized sound, see Jonathan Sterne, The Audible Past: Cultural Origins of Sound Reproduction (Durham, NC: Duke University Press, 2003), 34-35.

11. Giovanni Arrighi, The Long Twentieth Century: Money, Power, and the Origins of Our Times (London: Verso, 2010).

12. I draw heavily on Amy Glasmeier, Manufacturing Time: Global Competition in the Watch Industry, 1795-200o (New York: Guilford, 2000), 88-106 (on Swiss watchmaking), 107-129 (on US watch production), 130-154 (on subsequent competition between the two), and ${ }_{155^{-177}}$ (on the Japanese watch industry).

13. This is in comparison to Britain. See Glasmeier, Manufacturing Time, 92.

14. Glasmeier, Manufacturing Time, 128.

15. Glasmeier, Manufacturing Time, 177.

16. Glasmeier, Manufacturing Time, 177; figures from Table 8.4 (174-175).

17. On the Japanese and US-American scientists, entrepreneurs, and companies involved, see Bob Johnstone, We Were Burning:Japanese Entrepreneurs and the Forging of the Electronic Age (Boulder, CO: Basic Books, 1999), 1-117. On Japanese economic competitiveness vis-à-vis the US in relative capital and labor costs during the 1970s-80s and decreasing US advantages in energy prices (due to the 1973 and 1979 energy crises), see Dale Jorgenson and Masahiro Kuroda, "Productivity and International Competitiveness in Japan and the United States, 1960-1985," in Productivity Growth in Japan and the United States, ed. Charles Hulten (Chicago: University of Chicago Press, 1990), 29-57, especially 38-41. The pre-OPEC oil crisis period (1968-1973) witnessed intensive Japanese $\mathrm{R} \& \mathrm{D}$ investment in primary electrical and electronics technologies, leading to a large accumulation of $R \& D$ stock (including in semiconductor microchip manufacturing) that propelled the digital watch market in the mid-1970s and after, continuing post-crisis and scaling upward more effectively in Japan than the US. See M. Ishaq Nadiri and Ingmar R. Prucha, "Comparison and Analysis of Productivity Growth and R\&D Investment in the Electrical Machinery Industries of the United States and Japan," in Productivity Growth in Japan and the United States, 109-133.

18. "Swatch," Wikipedia, http://en.wikipedia.org/wiki/Swatch, accessed October 21, 2019.

19. Perry Anderson, "Jottings on the Conjuncture," New Left Review II/48 (November-December 2007), 6 .

20. See, for example, Mizuko Ito, et al., eds., Personal, Portable, Pedestrian: Mobile Phones in Japanese Life (Cambridge, MA: MIT Press, 2005).

21. See Shaul Katzir, The Beginnings of Piezoelectricity: A Study in Mundane Physics (Dordrecht: Springer, 2006); also, see Takuro Ikeda, Fundamentals of Piezoelectricity (Oxford: Oxford University Press, 1996), 1-3; and "Quartz Clock," Wikipedia, http://en.wikipedia.org/wiki/Quartz_clock, accessed May 21, 2009. 
22. David Landes, Revolution in Time: Clocks and the Making of the Modern World (Cambridge, Mass.: Belknap Press, 1983), 342-3 and esp. 377.

23. See "Watch," Wikipedia, http://en.wikipedia.org/wiki/Wristwatch, accessed May 21, 2009; and Carlene Stephens and Maggie Dennis, "Engineering Time: Inventing the Electronic Wristwatch," British Journal of the History of Science 33 (2000): 492-4.

24. See the Bond film clip at http://www.oldpulsars.com/ as of October 26, 2019.

25. Glasmeier, Manufacturing Time, 209.

26. Ernest Braun and Stuart MacDonald, Revolution in Miniature: The History and Impact of Semiconductor Electronics, rev. 2nd ed. (Cambridge: Cambridge University Press, 1982), 181-183.

27. See the Rotary ad here https://www.youtube.com/watch?v=G4Zfwq_2hLk (accessed October 26, 2019) and the Seiko ad here https://www.youtube. com/watch?v=IrP79jWm3Qc (accessed October 26, 2019).

28. See "Making the Digital Watch Serve the Customer," in Tom Hyltin, The Digital Electronic Watch (New York: Van Nostrand Reinhold, 1978), 39-40.

29. Susan Kuzca, untitled, United Press International, 3 June 1981.

30. Pieter Doensen, Watch: History of the Modern Wristwatch:Design 1950-1983, Electric 1950-1993 (Gent: Snoeck Ducaju \& Zoon, 1994), 197; anonymous, Casio press release, PR Newswire, 12 June 1980.

31. Japan joined the newly formed G6 in 1975 with France, Italy, West Germany, the UK, and US.

32. “Q\&A: How Alarm Watches Make Their Noise," New York Times, 15 August 1989.

33. See Larry Humes, "What Is 'Normal Hearing' for Older Adults and Can 'Normal-hearing Older Adults' Benefit from Hearing Care Intervention?", The Hearing Review, July 14, 2020, https://www.hearingreview.com/inside-hearing/research/what-is-normal-hearing-for-older-adults, accessed September 6, 2020.

34. Indeed, $4096 \mathrm{~Hz}$ is close to the frequency with the lowest decibel threshold; see the chart in R. Murray Schafer, The Soundscape: Our Sonic Environment and the Tuning of the World (Rochester, VT: Destiny Books, 1994), 116. Thanks to Anand Gopinath, who suggested price determined the watch alarm signal's frequency and mode of amplification.

35. On the running boom, see Sumanth Gopinath and Jason Stanyek, "Tuning the Human Race: Athletic Capitalism and the Nike+ Sport Kit," in Music, Sound, and Space: Transformations of Public and Private Experience, ed. Georgina Born (Cambridge University Press, 2013), 128-148. Also see E. P. Thompson, "Time, Work-Discipline, and Industrial Capitalism," Past \& Present 38 (1967), 56-97.

36. James P. Sterba, "By 1990, Modern Quartz Will Have Nearly Silenced the Tick," New York Times, 9 February 1982.

37. Landes, Revolution in Time, 353; Richard Porch, "The Digital Watch: Tribal Bracelet of the Consumer Society," Design Issues 2/2 (Autumn 1985), 46.

38. Martin Smith (of the Orange County Register), "Technology's Timebomb Ticks," The Oregonian, 3 January 1989. 
39. Editorial, "Modern Times: Beeps," New York Times, 18 January 1982. In meetings during my father's employment at Pullman in the late 1970s-early 1980 s, watches would start to beep around the hour, and the presiding works manager would get annoyed and stop these meetings temporarily. Digital watches were typically owned by men; this may still be true today. (The gendering of the digital watch merits much greater study.) Sudhir Gopinath, conversation on August 21, 2013.

40. Glasmeier, Manufacturing Time, 255. Moreover, as luxury goods, mechanical watches made a comeback. See Joe Thompson, "Mechanical Watches Almost Disappeared Forever. Here's How They Didn't," Bloomberg, 4 January 2018, https://www.bloomberg.com/news/articles/2018-01-04/ how-mechanical-watches-survived-after-quartz-a-concise-history, accessed September 1, 2020.

41. Carlene Stephens and Maggie Dennis, "Engineering Time: Inventing the Electronic Wristwatch," British Journal for the History of Science 33 (2000), 497.

42. See Mike Murphy, "The Apple Watch is a Great Smart Watch and Finally a Good Dumb One Too," Quartz, 23 October 2019, https://qz.com/1719176/theapple-watch-series-5-is-the-best-one-yet/, accessed October 26, 2019.

43. Older smartwatches were peripherals, dependent on stronger devices. Susan Ryan, Garments of Paradise: Wearable Discourse in the Digital Age (Cambridge, Mass.: MIT Press, 2014), 235.

44. Annie Van Cleve, "A Time for Youth: Wristwatch Losing Ground in HighTech World," The Capital Times (Madison, WI), December 1, 2006, http:// watch-talk.blogspot.com/2006/12/wristwatch-losing-ground-in-high-tech. html, accessed 9 September 2014. Also see "Smartwatch," Wikpedia.org, http://en.wikipedia.org/wiki/Smartwatch, accessed October 22, 2019.

45. Landes, Revolution in Time, 365. After WWII, "cheap time" was purveyed most by US-based budget watchmaker Timex.

46. See my The Ringtone Dialectic: Economy and Cultural Form (Cambridge, MA: MIT Press, 2013).

47. See Larissa Hjorth, "Odours of Mobility: Mobile Phones and Japanese Cute Culture in the Asia-Pacific," Journal of Intercultural Studies 26 (2005), 39-55; and Sianne Ngai, Our Aesthetic Categories: Zany, Cute, Interesting (Cambridge, MA: Harvard University Press, 2012), 77-86.

48. See Melissa Gregg and Tamara Kneese, "Clock," in Timon Beyes, et al., The Oxford Handbook of Media, Technology, and Organization Studies (New York: Oxford University Press, 2019), 95-105.

49. Scientific pitch, present in older digital casino games and slot machines (also tuned to scientific $\mathrm{C}$ ) as well as digital watches and alarms, is an underappreciated facet of the auditory culture of an older digital modernity. Thanks to Dan Melamed for this argument. Also see Bruce Haynes, A History of Performing Pitch: The Story of 'A' (Lanham, MD: Scarecrow Press, 2002), 42, and "The Science of Music: What Is Beauty, and Why Is It Necessary?", The Schiller Institute, n.d., https://archive.schillerinstitute.com/ music/rev_verdituning.html, accessed October 22, 2019. 


\section{About the Author}

Sumanth Gopinath is Associate Professor of Music Theory in the School of Music at the University of Minnesota. His research interests include musical minimalism, sound studies, new media, and experimental and popular music. He is the author of The Ringtone Dialectic and co-edited volumes on mobile music and Steve Reich. 